\title{
Factors impacting hospital avoidance program utilisation in the care of acutely unwell residential aged care facility residents
}

\author{
Luke Testa*, Tayhla Ryder, Jeffrey Braithwaite and Rebecca J. Mitchell
}

\begin{abstract}
Background: An existing hospital avoidance program, the Aged Care Rapid Response Team (ARRT), rapidly delivers geriatric outreach services to acutely unwell or older people with declining health at risk of hospitalisation. The aim of the current study was to explore health professionals' perspectives on the factors impacting ARRT utilisation in the care of acutely unwell residential aged care facility residents.

Methods: Semi-structured interviews were conducted with two Geriatricians, two ARRT Clinical Nurse Consultants, an ED-based Clinical Nurse Specialist, and an Extended Care Paramedic. Interview questions elicited views on key factors regarding care decisions and care transitions for acutely unwell residential aged care facility residents. Thematic analysis was undertaken to identify themes and sub-themes from interviews.

Results: Analysis of interviews identified five overarching themes affecting ARRT utilisation in the care of acutely unwell residents: (1) resident care needs; (2) family factors; (3) enabling factors; (4) barriers; and (5) adaptability and responsiveness to the COVID-19 pandemic.

Conclusion: Various factors impact on hospital avoidance program utilisation in the care of acutely unwell older aged care facility residents. This information provides additional context to existing quantitative evaluations of hospital avoidance programs, as well as informing the design of future hospital avoidance programs.
\end{abstract}

Keywords: Aged, Aged, 80 and over, COVID-19, Health Services for the Aged, Nursing homes, Patient care team, Patient transfer, Referral and consultation

\section{Introduction}

Population ageing is occurring in many countries, including Australia [1]. Ageing is associated with multiple chronic health conditions and greater use of health and aged care services $[2,3]$. Rising hospital service utilisation has been observed, with older people overrepresented in the hospitalised population [4]. Residential aged care facility (RACF) residents (also known as

\footnotetext{
*Correspondence: luke.testa@mq.edu.au

Australian Institute of Health Innovation, Macquarie University, Level 6, 75 Talavera Road, Sydney, NSW 2109, Australia
}

nursing home residents) are a vulnerable population that experience greater challenges and poorer outcomes when transferring from the RACF to Emergency Departments (EDs) [5].

Care for acutely unwell RACF residents for some health conditions can potentially be delivered outside of an acute hospital setting [6]. It has been previously estimated that $5-60 \%$ of resident transfers to EDs are avoidable [3]. Hospital avoidance programs have been designed and implemented in multiple aged care settings to reduce unnecessary ED transfers and the associated

(c) The Author(s). 2021 Open Access This article is licensed under a Creative Commons Attribution 4.0 International License, which permits use, sharing, adaptation, distribution and reproduction in any medium or format, as long as you give appropriate credit to the original author(s) and the source, provide a link to the Creative Commons licence, and indicate if changes were made. The images or other third party material in this article are included in the article's Creative Commons licence, unless indicated otherwise in a credit line to the material. If material is not included in the article's Creative Commons licence and your intended use is not permitted by statutory regulation or exceeds the permitted use, you will need to obtain permission directly from the copyright holder. To view a copy of this licence, visit http://creativecommons.org/licenses/by/4.0/ The Creative Commons Public Domain Dedication waiver (http://creativecommons.org/publicdomain/zero/1.0/) applies to the data made available in this article, unless otherwise stated in a credit line to the data. 
risks, such as care complications [7-10]. A variety of approaches to reducing avoidable hospital admissions have been used, with mixed results [11].

An existing hospital avoidance program, the Aged Care Rapid Response Team (ARRT), rapidly delivers geriatric outreach services to older people in declining health or acutely unwell and at risk of hospitalisation [12]. Previously, analysis of data collected by ARRT over a three year period indicated that residents were successfully managed within their RACF on $85 \%$ of occasions and hospital transfer was potentially avoided on almost half of occasions [12]. Additionally, the effect of ARRT on health service utilisation and resident health outcomes found that residents reviewed by ARRT who were subsequently hospitalised had an average reduction of 9-10 days in hospital length of stay and AUD\$2000-\$8000 in hospital treatment costs compared to residents receiving usual care [12].

The ARRT model of care is complex and contains multiple service elements, including a geriatric outreach service, coordination of resident care, and capability building of RACF staff. Identifying the elements that influence resident outcomes will aid in future hospital avoidance model design and subsequent implementation. The current study aims to explore health professionals' perspectives on the factors impacting ARRT utilisation in the care of acutely unwell residential aged care residents.

\section{Methods}

\section{Design}

Semi-structured interviews of health professionals working in the ARRT health service area were conducted. Two theoretical frameworks informed the approach: Donabedian's model [13] and the modified Andersen's health behavior model [14]. Donabedian's model provides a framework for evaluating health services using three separate but interrelated concepts: structure, process and outcome. Structure describes factors influencing the setting in which ARRT delivers care. e.g. physical, organisational and staffing characteristics. Process refers to all activities undertaken by ARRT that deliver and support resident care. Outcome refers to the effect of ARRT processes on residents, health professionals and the health system. Structures, processes and outcomes relating to ARRT were identified from reviewing the ARRT model of care and relevant literature $[11,15,16]$.

Andersen's health behavior model depicts health service utilisation as a consequence of three broad categories: need factors, predisposing factors and enabling factors. Previously, Andersen's health behavior model was adapted for the ED setting [17] and has been modified further for ED utilisation by older adults [14]. The modified Andersen's health behavior model conceptualises the unwell older person's need for ED transfer from a RACF in relation to the intensity of their health care needs (i.e. the predisposing factor). Enabling factors were conceptualised as those preventing ED transfers. The organisation of residents' health care needs in tandem with their need for ED transfer and enabling factors allowed the modified Andersen's health behavior model to be envisioned as a subset of Donabedian's model (Fig. 1). A priori categories relating to structures, processes and outcomes were used to guide the interview questions and analysis (Table 1).

Ethical approval for this evaluation was granted by the Northern Sydney Local Health District Human Research Ethics Committee (reference: RESP/18/247) and Macquarie University Human Research Ethics Committee (reference: 5201938347115).

Adapted from Donabedian's model [13] and a modified Andersen's health behavior model [14].

\section{Setting}

ARRT is a hospital-based service operating in Northern Sydney Local Health District (NSLHD), Australia. As of 30th June 2015, NSLHD had a population of approximately 900,000 , with an estimated $15.5 \%$ aged 65 years and older [18]. ARRT supports home and RACF-based management of older people at risk of hospitalisation, when appropriate, through the rapid delivery of outreach services to the Lower North Shore and Ryde/Hunters Hill regions of NSLHD. The ARRT service area encompasses 43 local RACFs (3344 RACF beds in total) and two public hospitals (a 720 bed and a 160 bed hospital). ARRT operates from Monday to Friday from 8 am to $4.30 \mathrm{pm}$ and is staffed by a hospital-based geriatrician, an aged care community registrar and two Clinical Nurse Consultants (CNCs). Referrals can be made to ARRT via telephone. There is a dedicated phone line for the ARRT service, as well as direct contact numbers for the CNCs and registrar for urgent referrals. Upon referral by RACF staff, the ARRT CNC/Registrar assess and triage the resident. Telehealth may be used to support the assessment and triage process. If a RACF visit is required, it will usually occur within $24 \mathrm{~h}$. Services provided by ARRT include: Comprehensive Geriatric Assessment, treatment of acute infections, liaison with other services e.g., NSW ambulance, mobile $x$-ray and ultrasound, falls assessment, pain management and medication review [19].

\section{Participants}

Purposive sampling [20] was used to identify a representative sample of health professionals involved in the care of unwell RACF residents, with the assistance of the ARRT Geriatrician. Ten potential participants were invited to join the study via email. This included two Geriatricians, two Aged Care Registrars, two ARRT 




Fig. 1 Structures, processes and outcomes of the Aged Care Rapid Response Team. RACF: Residential aged care facility

CNCs, one ED-based Clinical Nurse Specialist, one Extended Care Paramedic, one General Practitioner, and one RACF manager. If no response was received, a follow-up email was sent. Six participants consented to be interviewed and four did not respond. A date and time to be interviewed was organised at the discretion of the consenting participants. Participants were emailed an interview guide prior to their interview date. Participants were interviewed individually by LT.

\section{Data collection}

LT conducted semi-structured interviews via Zoom video conferencing in October 2020. At the time of the study, LT was a PhD candidate and Research Assistant with postgraduate qualifications in public health and research, and experience in collecting and analysing data from interviews and focus groups. Prior to the current study, LT co-authored two ARRT evaluation studies with two of the current study's participants. Before commencing interviews, all participants were informed that the current study formed part of LT's PhD. Interviews took between 15 and $70 \mathrm{~min}$ to complete. Each interview was audio recorded and transcribed verbatim. Notes were taken during and/or after interviews. Interview questions were asked to elicit descriptions on key factors regarding care decisions and care transitions for acutely unwell RACF residents, as well as the structures, processes and outcomes of the ARRT model of care (Appendix A). Staff outcomes were assessed using a singleitem job satisfaction measure [21] with an open-ended follow-up question.

\section{Data analysis}

Interview transcripts were imported to NVivo 12 [22] for coding and thematic analysis. A list of preliminary codes based on the a priori categories was created prior data collection. A coding system was adopted to encourage intercoder reliability and agreement [23]. An interview transcript was selected at random and dual coded by LT and TR. Coding was compared and discrepancies were discussed. Refinements to codes and definitions were suggested and mutually agreed upon. Where LT and TR could not reach agreement, RM provided guidance. The dual coding process was repeated two times until LT and TR were satisfied with modifications to the code list and the level of intercoder agreement. The remaining transcripts were then divided and coded individually.

Once coding was complete, data were charted into a framework matrix. Thematic analysis was undertaken by LT, in consultation with TR and RM. A gradual process of interrogating similarities and differences in the data using the framework matrix occurred. Themes and subthemes relating to the research question were identified. Preliminary findings were reviewed by LT, TR and RM.

\section{Member checking}

Member checking activities were undertaken in December 2020 in order to establish credibility of findings. This involved emailing participants a summary of emerging themes and sub-themes, along with illustrative quotes to elicit participant feedback. Participants confirmed that the emerging themes accorded with their perspectives.

\section{Rigour}

Rigour in qualitative research can be checked against four criteria: credibility, transferability, dependability, and confirmability [24]. Approaches used by the authors to ensure study rigour include: data triangulation through comparing individual viewpoints and experiences of the ARRT team against those of participants 
Table 1 A priori categories for structure, process and outcome elements of the Aged Care Rapid Response Team

\begin{tabular}{|c|c|}
\hline Category & Definition \\
\hline \multicolumn{2}{|l|}{ STRUCTURES } \\
\hline Resident health needs & The necessity of ED transfer and/or hospital admission when an RACF resident becomes unwell \\
\hline Comorbidity & The presence of two or more co-occurring medical conditions \\
\hline Functional decline & The loss of physical and/or cognitive abilities \\
\hline End of life & RACF residents at the end stage of life \\
\hline Family needs & Needs and expectations of the family of an unwell RACF resident \\
\hline Health professional & ARRT team roles (Geriatrician, Clinical Nurse Consultants, Aged Care Registrar) \\
\hline Experience & Experience required by ARRT staff to perform their role \\
\hline Knowledge & Knowledge required by ARRT staff to perform their role \\
\hline Skills & Skills required by ARRT staff to perform their role \\
\hline Organisation & Physical and organisational factors required to deliver ARRT \\
\hline Setting & Program description and characteristics \\
\hline Resources & Resources required by ARRT to operate. Includes access to technology. \\
\hline Workload & Amount/difficulty of work assigned to ARRT staff \\
\hline Barriers & Challenges in delivering ARRT \\
\hline Enablers & Facilitators for delivering ARRT \\
\hline Residential Aged Care Facility & RACF staff roles \\
\hline Training & Training required by RACF staff roles to perform their role \\
\hline Knowledge & Knowledge required by RACF staff to perform their role \\
\hline Skills & Skills required by RACF staff to perform their role \\
\hline \multicolumn{2}{|l|}{ PROCESSES } \\
\hline Proactive Care & A person-centred, preventative approach to the care of unwell RACF residents \\
\hline Access to skilled care providers & $\begin{array}{l}\text { Rapid access to appropriate decision making and care. Includes capacity to access additional expertise e.g. nurse } \\
\text { practitioners, allied health practitioners, pharmacists, geriatricians, palliative care specialists, medicolegal and referrals for } \\
\text { specialist services }\end{array}$ \\
\hline Coordinated care & Delivering care that is integrated between multiple providers and services \\
\hline CGA & An assessment of medical, social, and functional needs, and the development of a coordinated care \\
\hline Advance Care Planning & Resident's preferences for future care \\
\hline Capability building of RACF staff & Improving care through sharing knowledge and skills with RACF staff \\
\hline Risk stratification & Identification of RACF residents who are at risk of hospitalisation and likely to benefit from ARRT intervention \\
\hline Partnerships & Hospitals, RACFs, ambulance services and GPs working together to achieve shared goals \\
\hline Communication & Exchange of information regarding the care of RACF residents \\
\hline Interpersonal communication & Sharing of information between health professionals, RACF residents and the families via personal interactions \\
\hline Information transfer & The handover of resident health data from one care provider to another \\
\hline \multicolumn{2}{|l|}{ OUTCOMES } \\
\hline Resident health & Effect of ARRT on health of unwell RACF residents \\
\hline Resident managed in RACF & Factors involved in RACF-based management of unwell RACF resident \\
\hline Resident transferred to ED & Factors involved in ED transfer of unwell RACF residents \\
\hline Resident admitted to hospital & Factors involved in hospital admission of unwell RACF residents \\
\hline Adverse events & Adverse events associated with ED transfer/hospital admission of unwell RACF residents \\
\hline Health system utilisation & Effect of ARRT on the use of hospital services by unwell RACF residents \\
\hline Health professional & Effect of ARRT on health professionals involved in the care of unwell RACF residents \\
\hline $\begin{array}{l}\text { ADAPTABILITY AND } \\
\text { RESPONSIVENESS }\end{array}$ & ARRT's ability to adapt to changing circumstances e.g. pandemics/disasters \\
\hline COVID-19 & All COVID-19 information \\
\hline
\end{tabular}


external to the ARRT team, and through consulting organisational documents describing the ARRT service $[19,25]$; investigator triangulation through dual coding of data by a male and female researcher of different backgrounds and experiences [26]; the undertaking of member checking activities; reporting descriptive data relating to the study setting and context; and utilising the Consolidated Criteria for Reporting Qualitative Studies [27] in manuscript preparation.

\section{Results}

A total of six health professionals were interviewed, comprising three $(50.0 \%)$ nursing professionals, two (33.3\%) medical professionals, and one (16.7\%) paramedic professional. Four (66.7\%) participants were female and two (33.3\%) were male. Female participants were employed as nursing and paramedic professionals and male participants were employed as medical professionals. Five (83.3\%) participants were staff from the two hospitals operating within the ARRT service area, and one (16.7\%) was employed by NSW Ambulance. Of the five hospital staff, three (60.0\%) were ARRT staff (two Clinical Nurse Consultants and a Geriatrician), one (20.0\%) was an ED-based Clinical Nurse Specialist working specifically with older people who present to the ED, and one $(20.0 \%)$ was a Clinical Director and Geriatrician. When asked how they felt about their job as a whole, two (66.7\%) ARRT staff reported feeling extremely satisfied. One (33.3\%) ARRT staff reported feeling extremely satisfied pre-COVID-19 and moderately satisfied postCOVID-19.

Analysis of interviews identified five overarching themes affecting ARRT utilisation in the care of acutely unwell RACF residents: (1) resident care need factors; (2) family factors; (3) enabling factors; (4) barriers; and (5) adaptability and responsiveness (Table 2). Subthemes within themes were also identified.

\section{Theme 1 -resident care need factors}

Factors relating to resident care needs were the basis for considering whether specific resident health conditions were likely to benefit from ARRT intervention versus hospital treatment. When considering the risks and benefits of hospital transfer for unwell older RACF residents, participants recognised potential care complications for residents admitted to hospital. These care complications included delirium, falls and medication errors.

\section{Sub-theme 1.1- residents with cognitive impairment}

Five participants acknowledged that residents with cognitive impairment, such as delirium or dementia, were at risk of poor outcomes when transferred to hospital services. The ARRT geriatrician and $\mathrm{CNCs}$ considered the
RACF a suitable environment for the management of residents with cognitive impairment.

The type of patient [who would benefit most from ARRT] would be someone who's frail, who has dementia. That would be an example of condition where it's better for them not to be in hospital if you can avoid it. (G1) Geriatrician

\section{Sub-theme 1.2- residents at the end of life}

All participants emphasised the identification of, and advocacy for, end of life care needs and the use of advance care directives as an important factor in preventing unnecessary ED transfers and hospital admissions. One participant described how a lack of RACF staff experience can lead to unnecessary hospital transfer for residents.

And it's, it is very sad for people with dementia and things like that. [RACF staff] don't really understand the progression of dementia. They don't understand what end of life might look for these people, and how long that may progress for them. So they're kind of, I guess, sending people in unnecessarily, or you know, not instigating certain levels of care because of their lack of experience. (CNC1) ARRT Clinical Nurse Consultant

As with cognitive impairment, the RACF was considered a suitable environment for residents at the end of life.

\section{Theme 2-family factors}

All participants discussed the family of unwell residents as an important consideration in care planning and decisions. Understanding and navigating family needs and expectations was considered an essential, and at times complex, part of the health professional's role.

\section{Sub-theme 2.1-family needs and expectations}

Four participants described the potential for tension between providing RACF-based treatment for the resident and respecting the family's wishes for hospital treatment.

Families, I think, still see hospital is this gold standard of care, and it is. But I think it's very hard sometimes to explain to families that [for] their loved ones ... the outcome of the treatment of going into hospital may not necessarily change the position or change the condition for their family - for their loved ones. So, it's managing those expectations. (CNC1) ARRT Clinical Nurse Consultant

One participant described the potential for conflict between the resident's care preferences and the family's 
Table 2 Overview of interview themes and sub-themes with illustrative quotes from health professionals

\begin{tabular}{|c|c|c|}
\hline Theme & Sub-theme & Illustrative quotes \\
\hline $\begin{array}{l}\text { 1. Resident } \\
\text { care need } \\
\text { factors }\end{array}$ & $\begin{array}{l}1.1 \text { Residents } \\
\text { with cognitive } \\
\text { impairment }\end{array}$ & $\begin{array}{l}\text { "The type of patient [who would benefit most from ARRT] } \\
\text { would be someone who's frail, who has dementia. That } \\
\text { would be an example of condition where it's better for them } \\
\text { not to be in hospital if you can avoid it." (G1) Geriatrician }\end{array}$ \\
\hline
\end{tabular}

1.2 Residents at "If they're palliative, if they are dying, they can be cared for the end of life in the majority of facilities - they can be cared for at the facility." (CNC2) ARRT Clinical Nurse Consultant

\begin{tabular}{|c|c|c|}
\hline $\begin{array}{l}\text { 2. Family } \\
\text { factors }\end{array}$ & $\begin{array}{l}2.1 \text { Family } \\
\text { needs and } \\
\text { expectations }\end{array}$ & $\begin{array}{l}\text { "Families, I think, still see hospital is this gold standard of } \\
\text { care, and it is. But I think it's very hard sometimes to explain } \\
\text { to families that [for] their loved ones... the outcome of the } \\
\text { treatment of going into hospital may not necessarily change } \\
\text { the position or change the condition for their family - for } \\
\text { their loved ones. So it's managing those expectations." } \\
\text { (CNC1) ARRT Clinical Nurse Consultant }\end{array}$ \\
\hline $\begin{array}{l}\text { 3. Enabling } \\
\text { factors }\end{array}$ & $\begin{array}{l}\text { 3.1 Rapid } \\
\text { geriatric } \\
\text { outreach } \\
\text { service }\end{array}$ & $\begin{array}{l}\text { "[ARRT has the] ability to provide medical care outside of the } \\
\text { hospital, and that includes comprehensive geriatric } \\
\text { assessments. That includes provision of certain treatments. } \\
\text { So things like antibiotics, fluids, ability to do blood testing, } \\
\text { ability to do things like diagnostics. Things like ECGS, bladder } \\
\text { scanners, mobile X-ray." (G1) Geriatrician }\end{array}$ \\
\hline
\end{tabular}

3.2 Coordination of you've got the aged care, you've got APAC [Acute Post-Acute care

3.3 Telehealth "We're doing so many video conferences - that our capacities, it's allowed our capacity to build up because you don't need to go and do the reviews on site. Two reviews this morning already." (CNC2) ARRT Clinical Nurse Consultant

3.4 Relevant "We just work collaboratively. I think that is key to how the skills within the team actually works." (CNC2) ARRT Clinical Nurse ARRT team Consultant

3.5 Relationships with other services

3.6 Capability building of RACF staff

4. Barriers

4.1 Team size
"Develop good relationships with your aged care facilities and your GP's that are working within them ... it just opens up the pathway of referral. Developing pathways from NSW Ambulance into teams like the ARRT service, really developing good relationships with them as well, really opens up the ability to ... intercept ambulances." (CNC1) ARRT Clinical Nurse Consultant

"While [reducing unnecessary hospital admissions is] our primary goal, our secondary goal, which is also very important, is educating, upskilling and providing support for aged care facility staff ... with a similar goal in mind." (G1) Geriatrician 1 working on coronavirus planning for nursing homes, which is entirely separate to our usual business. So time, inadequate numbers of staff. Although we're trying to
[ARRT is able to give a resident with delirium] treatment that they would get in hospital, in a much more conducive environment to their actual health and wellbeing. They're definitely reducing the adverse effects that they would be exposed in hospital." (CNC1) ARRT Clinical Nurse Consultant

"We liaised with a palliative care team that hadn't spoken to her for a few months. And we liaised with ARRT and we did a video conference. And we ended up providing care for her at home that then she was able to pass away after we'd implemented care. Which was amazing and it's exactly what she wanted." (ECP) Extended Care Paramedic

"There are benefits [of RACF-based management of residents] to the family. The patients kept where they are [and] the family can still visit, can be involved in their care." (G1) Geriatrician

We're doing lots of acute assessments of patients ... assessing if they've been unwell, assessing if they've got any sort of major things that we can reverse, but ultimately trying to keep them in the ... aged care facility as well ... Trying to treat them or apply sort of acute management outside of hospital." (CNC1) ARRT Clinical Nurse Consultant

When I get the phone call from ARRT ... I can just basically lookout for the patient as soon as they get on the screen. We can then kind of grab the medical team and say "Hey, let's quickly get someone on it", you know, get them seen quickly, get them their scans happening, and then try and get them out quickly. So if someone didn't jump on board, they may sit in the ambo bay for - I don't know how many hours... I do think that we can fast track them through [ED] to a degree." (CNS) ED-based Clinical Nurse Specialist

You know, within 5 to 10 min we can start up a video conference with someone in an age care facility." (G1) Geriatrician 1

"IARRT] staff need to be relatively independent and relatively senior and experienced and able to deal flexibly with problems. I think those would be the core components, senior medical, senior nursing and a flexible approach to management." (G1) Geriatrician

"I personally think they're amazing. It's a really good service. It ticks the boxes for getting the right patient, the right care, in the right place. And they're so easy to liaise with, and yeah just fantastic." (ECP) Extended Care Paramedic

"Building up the capacity within the nursing staff. So that they can recognise deterioration early, that they feel more competent and confident they can manage more acutely unwell people." (CNC2) ARRT Clinical Nurse Consultant

"We're a small team. It would be great to have a bigger team. Something that we - and I guess that's another barrier, is if we had more geriatricians, more staff, more expertise in the field, Allied Health that worked directly 
Table 2 Overview of interview themes and sub-themes with illustrative quotes from health professionals (Continued)

\begin{tabular}{|c|c|c|c|}
\hline Theme & Sub-theme & Illustrative quotes & \\
\hline & & $\begin{array}{l}\text { address that too. We were actually recruiting a lot of people } \\
\text { recently." (G1) Geriatrician }\end{array}$ & $\begin{array}{l}\text { with us, we might be able to achieve a lot of different } \\
\text { things." (CNC1) ARRT Clinical Nurse Consultant }\end{array}$ \\
\hline & $\begin{array}{l}4.2 \text { Hours of } \\
\text { operation }\end{array}$ & $\begin{array}{l}\text { "Extended hours and weekends covered would be great... A } \\
\text { lot of the time health issues arise, it's not on a Monday- } \\
\text { Friday 9-5." (ECP) Extended Care Paramedic }\end{array}$ & $\begin{array}{l}\text { "A lot of residential aged care patients do come in [to } \\
\text { the ED] after hours, because they haven't got services } \\
\text { like aged care rapid response after hours... [They] do } \\
\text { tend to come quite regularly after hours, and we don't } \\
\text { have that support then." (CNS) ED-based Clinical Nurse } \\
\text { Specialist }\end{array}$ \\
\hline $\begin{array}{l}\text { 5. Adaptability } \\
\text { and } \\
\text { responsiveness }\end{array}$ & $\begin{array}{l}\text { 5.1 The COVID- } \\
19 \text { pandemic }\end{array}$ & $\begin{array}{l}\text { "Coronavirus has probably improved [communication } \\
\text { between the hospital and RACFs] too. Because we're } \\
\text { increasing talking to the nursing home. We're actually } \\
\text { having face to face sessions with them. Trying to upskill } \\
\text { them, and I guess all that raises awareness of what we're } \\
\text { doing." (G1) Geriatrician }\end{array}$ & $\begin{array}{l}\text { "TThe hospital is] much more engaged and [RACFs\} are } \\
\text { much more engaged than they were six months ago, } \\
\text { before the COVID. And particularly the last four months } \\
\text { when the realisation of the devastating impact that that } \\
\text { disease might have. There's much more communication, } \\
\text { and we're out there training them on PPE, and infection } \\
\text { control measures, right now. So that, in that very } \\
\text { focused way we're much more engaged together. Prior } \\
\text { to that, it was spotty. Some places did well, and others, } \\
\text { we hardly made much penetration in to at all." (G2) } \\
\text { Geriatrician }\end{array}$ \\
\hline
\end{tabular}

care preferences, and how they can navigate this conflict with interpersonal communication.

\section{A lot of the times we'll go to [RACFs], they've got an advance care plan, but the family will try and over- ride that ... At the end of the day, the patient's rights are there. But if they're not able to communicate those anymore. It's the ability of the paramedic to communicate well with the family, I think. Get them on board, discuss with them what really they want happening, adverse to what they think should hap- pen. And you can get the GP onboard as well and have a little chat, and I think, allay the fears. Cause I think a lot of the time people just think, oh just take them to hospital, they'll be OK. But at the end of the day, the condition probably isn't going to change. (ECP) Extended Care Paramedic}

Three participants viewed providing geriatric outreach services to RACFs as potentially benefitting families as well as residents.

There are benefits [of RACF-based management of residents] to the family. The patients kept where they are [and] the family can still visit, can be involved in their care. (G1) Geriatrician

\section{Theme 3-enabling factors}

Enabling factors related to ARRT's service elements. Notably, this included the provision of rapid geriatric outreach to RACFs, the coordination of care between services and providers, the utilisation of telehealth, relevant skills within the ARRT team, ARRT's relationship with other services, and providing capability building opportunities for RACF staff.

\section{Sub-theme 3.1-rapid geriatric outreach service}

ARRT was noted for its ability to provide acute care outside of a hospital environment.

[ARRT has the] ability to provide medical care outside of the hospital, and that includes comprehensive geriatric assessments. That includes provision of certain treatments. So things like antibiotics, fluids, ability to do blood testing, ability to do things like diagnostics. Things like ECGS, bladder scanners, mobile X-ray. (G1) Geriatrician

\section{Sub-theme 3.2-coordination of care}

In addition to providing outreach services to RACFs, ARRT can facilitate the fast tracking of residents through the ED via the ED-based Clinical Nurse Specialist, as well as refer residents to other specialities e.g. Allied Health.

When I get the phone call from ARRT ... I can just basically lookout for the patient as soon as they get on the screen. We can then kind of grab the medical team and say "Hey, let's quickly get someone on it", you know, get them seen quickly, get them their scans happening, and then try and get them out quickly. So if someone didn't jump on board, they may sit in the [ambulance] bay for - I don't know how many hours ... I do think that we can fast track them through [ED] to a degree. (CNS) ED-based Clinical Nurse Specialist 


\section{Sub-theme 3.3-telehealth}

In July 2019, ARRT piloted the use of telehealth in five RACFs. Telehealth has since expanded to include all RACFs in the local service area. The use of telehealth was noted to greatly increase the ARRT team's capacity and response time.

We're doing so many video conferences ... it's allowed our capacity to build up because you don't need to go and do the reviews on site. Two [resident] reviews this morning already. (CNC2) ARRT Clinical Nurse Consultant

\section{Sub-theme 3.4- relevant skills within the ARRT team}

The composition of the ARRT team was noted by participants to be a key enabler of the ARRT service.

I don't think ARRT would run without medical support. I think they need that, and relatively senior medical support. Similarly, I think that the, it wouldn't run without nursing, without a nursing team. It might, but it would be a much smaller service and less capable... I think all of our staff need to be relatively independent and relatively senior and experienced and able to deal flexibly with problems. I think those would be the core components lof ARRT], senior medical, senior nursing and a flexible approach to management. (G1) Geriatrician

\section{Sub-theme 3.5-relationships with other services}

The development of good relationships with other services and providers was seen by the ARRT team to encourage referral to ARRT. This sentiment was echoed by participants external to the ARRT team.

I personally think they're amazing. It's a really good service. It ticks the boxes for getting the right patient, the right care, in the right place. And they're so easy to liaise with, and yeah just fantastic. (ECP) Extended Care Paramedic

\section{Sub-theme 3.6-capability building of RACF staff}

Capability building of RACF staff is considered an important function of ARRT. Along with providing outreach services, capability building was perceived as helpful in reducing avoidable hospital admissions through empowering RACF staff to more effectively manage acutely unwell residents.

Building up the capacity within the nursing staff. So that they can recognise deterioration early, that they feel more competent and confident they can manage more acutely unwell people. (CNC2) ARRT Clinical Nurse Consultant

\section{Theme 4-barriers}

Barriers to the utilisation of ARRT related to team size and the lack of support after hours and on weekends.

\section{Sub-theme 4.1-team size}

The small number of staff employed by ARRT was seen to create some restriction in terms of achievement. This was particularly amplified by the COVID-19 pandemic.

We're a small team. It would be great to have a bigger team. Something that we - and I guess that's another barrier, is if we had more geriatricians, more staff, more expertise in the field, Allied Health that worked directly with us, we might be able to achieve a lot of different things. (CNC1) ARRT Clinical Nurse Consultant.

\section{Sub-theme 4.2-hours of operation}

Health professionals external to the ARRT team expressed a desire for ARRT to extend its coverage to after hours and weekends.

A lot of residential aged care patients do come in [to the ED] after hours, because they haven't got services like aged care rapid response after hours... [They] do tend to come quite regularly after hours, and we don't have that support then. (CNS) ED-based Clinical Nurse Specialist

Theme 5-adaptability and responsiveness

ARRT's ability to adapt to changing circumstances was discussed in the context of the COVID-19 pandemic.

\section{Sub-theme 5.1-the COVID-19 pandemic}

The COVID-19 pandemic saw an increase in ARRT's activity. In February/March 2020, the use of telehealth rapidly expanded from five pilot RACF sites to all 43 local RACFs within the ARRT service area.

Since COVID hit - I really notice the difference in what we can achieve, how we will be utilising teleconferencing, and it really does change, I guess, your ability to be quick and rapid for your patient. You just understand it a whole lot more, and you're not relying so much on what actually someone's telling you or how panicked, you know? People do tend to panic if the patient's unwell. You're not necessarily getting a very clear picture. Whereas, if you can see them, and you can ask them questions, you can assess them over the phone. We can do very simple assessments with aged care facility staff ... It's definitely been a crucial change in what we do. (CNC2) ARRT Clinical Nurse Consultant

In response to the COVID 19 pandemic, the capacity building component of ARRT services expanded to 
cover outbreak management preparation and training of RACF staff. Participants reflected that communication and partnerships between the hospital and local RACFs was enhanced post-COVID-19

[In addition to our normal activities] we have all the coronavirus stuff ... face-to-face meetings, talking through outbreak management plans, and actually doing visits where we go out and site visit and work out if they'll manage if there's a coronavirus outbreak there. So there's a lot of upskilling going on at the moment. (G1) Geriatrician

[The hospital is] much more engaged and [RACFs] are much more engaged than they were six months ago, before the COVID ... There's much more communication, and we're out there training them on $P P E$, and infection control measures, right now. So that, in that very focused way we're much more engaged together. Prior to that, it was spotty. Some places did well, and others, we hardly made much penetration in to at all (G2) Geriatrician

Funding was sought to expand the ARRT team. As of October 2020, when interviews were conducted, ARRT was in the process of hiring additional medical, nursing and allied health staff.

You know we're talking about our service, how good we are, we're giving them our figures and they're enhancing our staff at the moment because of COVID. We aren't a team that sat back and just let it happen. It's like no, we need this, we need that, we need this person in the position, we need this person in that position. We're not gonna just accept what you give us. (CNC2) ARRT Clinical Nurse Consultant

\section{Discussion}

This study identified factors affecting ARRT utilisation in the care of acutely unwell RACF residents, as perceived by health professionals. Resident care needs and family needs and expectations were recognised as contributing factors for resident care decisions and care plans. ARRT's service elements were recognised as enabling factors for hospital avoidance, as was ARRT's adaptability and responsiveness to the COVID-19 pandemic.

RACF residents with cognitive impairment were identified by participants as more suitable for RACF-based treatment than hospital-based treatment. Notably, an analysis of hospital service use trajectories of RACF residents reviewed by ARRT found residents living with dementia were more likely to be low hospital service users, compared to higher hospital service users [28]. Similarly, international studies have identified lower hospital service use in RACF residents with dementia, compared to residents without dementia [29-31]. There is evidence to suggest that care for residents with dementia may prioritise end of life care strategies, rather than active treatment, which may explain lower hospital service use by this cohort [32].

Family needs and expectations were recognised as an important and complex component of resident care decisions and planning, particularly when it came to residents at the end of life. Likewise, a qualitative study exploring factors influencing the transfer of Australian RACF residents to the ED found it was common for RACF staff to feel pressured by a resident's family to seek active treatment for residents at the end of life, and therefore they were more likely to transfer the resident to the ED [15]. Furthermore, an evaluation of an Australian aged care nurse practitioner-based hospital avoidance service found that nurse practitioner consultation with the unwell RACF resident and their family was a major contributor to resident and family satisfaction, as well as hospital avoidance [33]. The use of advance care directives were noted as an important factor in preventing unnecessary ED transfers and hospital admissions. Comparably, two quasi-experimental studies investigating the use of advance care planning tools for RACF residents found reduced hospital admissions [34, 35].

.ARRT's key service elements are providing rapid geriatric outreach to RACFs, coordinating care between health services and aged care providers, the utilisation of telehealth, skills within the ARRT team, forming relationships with other services, and capability building of RACF staff. Previously, an integrative review investigating models of care that avoid or improve transitions to hospital services for RACF residents found that whilst there is great heterogeneity amongst models, there is some evidence that the provision of geriatric outreach services to RACFs and the capability building of RACF staff may prevent some types of hospital admissions [11]. The review also reported a case study assessing the feasibility of telemedicine in providing geriatric services to RACF residents and found telemedicine may result in increased productivity and savings. Furthermore, evidence from a quasi-experimental evaluation of health outcomes of aged care residents that use ARRT services suggests that ARRT has a high success rate of RACFbased treatment of residents, as well as in reducing hospital length of stay and in hospital treatment costs compared to residents receiving usual care [12].

The results of the quasi-experimental evaluation on their own may suggest further evidence supporting the provision of geriatric outreach services to RACFs and capability building of RACF staff by hospital avoidance programs. At the same time, it should be noted that participants of the current study emphasised relevant skills 
within the ARRT team and the quality of relationships with other services as enablers of ARRT's success. Similarly, a structure and process evaluation of an Australian hospital avoidance program found that collaboration and effective communication and referral facilitates the provision of geriatric outreach services to RACF residents [36]. Additionally, a qualitative evaluation of stakeholder perspectives on transitions of RACF residents to EDs in two Canadian provinces found that successful transitions were influenced by effective communication and positive relationships with families and other providers [37]. Furthermore, a qualitative study exploring RACF staff and GP perspectives on RACF-based management and ED transfer of unwell residents in NSW, Australia stated that positive care transitions for unwell residents could be facilitated by developing positive relationships; and communication and collaboration between RACFs, ambulance, EDs and GPs [16]. Finally, an interview study investigating decision making around hospital transfer and/or referral to a geriatric outreach service in Melbourne, Australia discovered that the availability of timely and appropriately skilled medical and nursing staff to RACFs greatly influenced care decisions [38]. Therefore, when designing and implementing hospital avoidance models of care, consideration must be given to team skills, interpersonal communication, and relationship building with families and other health care providers. This underscores the importance of conducting mixed methods evaluation of complex interventions, with qualitative studies able to provide key context factors to enhance quantitative findings.

The COVID-19 pandemic has disrupted clinical and aged care in RACFs, necessitating quick adaption and response by health care teams to ensure they're meeting the care needs of this especially vulnerable population [39]. ARRT has demonstrated adaptability and responsiveness to the COVID-19 pandemic. Prior to the pandemic, ARRT piloted the use of telehealth in five local RACFs. In response to COVID-19, ARRT expanded telehealth to include all RACFs in the local service area. The introduction and utilisation of teleconferencing was seen to enhance the rapidness of ARRT's assessment and response to unwell residents. In addition to the expansion of telehealth, ARRT was involved in coronavirus planning and outbreak management with RACFs. This extra activity overwhelmed the ARRT team, leading them to seek additional funding and recruit additional medical, nursing and allied health staff. Similarly, a rapid exploration of emerging evidence regarding the care of older people during COVID-19 found evidence that health and social care teams can transform very rapidly in response to COVID-19, with goodwill driving much of this change. Team transformation included the use of telehealth, increased trust and collaboration within teams; and teams feeling empowered to drive change at a local level [39]. Given the paucity of evidence concerning hospital-based versus RACF-based treatment of older RACF residents with COVID-19 [40], the current study provides further evidence of a health team transforming in response to a pandemic.

\section{Limitations}

The geographic coverage of ARRT and the hours that ARRT is available, as well as the healthcare system it operates within, limit the generalisability of the current study's findings. Local healthcare system and population differences should be considered when interpreting the current study's findings. It was the intention of the current study to incorporate the views of RACF staff and General Practitioners. However, recruitment of interview participants occurred after the COVID-19 lockdown in Australia. Although attempts were made to recruit RACF staff and General Practitioners, these attempts were unsuccessful. Nonetheless, the current study's findings concerning the promotion of communication and relationship building between services is supported by a study solely utilising the perspective of RACF staff and GPs in a similar setting. Future research should incorporate the views of RACF staff, General Practitioners, and Paramedics other than Extended Care Paramedics, as well as the views of RACF residents and family members.

\section{Conclusion}

The current study has identified various factors impacting hospital avoidance program utilisation in the care of acutely unwell aged care residents. Notably, this includes providing access to timely and skilled care, promoting interpersonal communication and relationships, and transformation in response to the COVID-19 pandemic. The current study may provide additional context to existing quantitative evaluations of hospital avoidance programs, as well informing the design of future hospital avoidance programs.

\section{Abbreviations \\ ARRT: Aged Care Rapid Response Team; ED: Emergency Department; NSLH D: Northern Sydney Local Health District; RACF: Residential Aged Care Facility}

\section{Supplementary Information}

The online version contains supplementary material available at https://doi. org/10.1186/s12913-021-06575-1

Additional file 1.

Acknowledgements

The authors wish to thank the ARRT staff. 


\section{Authors' contributions}

$L T$, RM and JB conceptualised the study. LT conducted the interviews. $L T$ and TR coded the interview data. LT performed data analysis, in consultation with TR and RM. LT wrote the first draft of the manuscript. All authors were involved in subsequent manuscript revisions.

\section{Authors' information}

Affiliations.

Australian Institute of Health Innovation, Macquarie University, Level 6, 75 Talavera Road, Macquarie University NSW Australia.

Luke Testa; Tayhla Ryder; Jeffrey Braithwaite; Rebecca J Mitchell.

\section{Funding}

LT is supported by a Macquarie University Faculty of Medicine and Health Science Ph.D. Scholarship.

\section{Availability of data and materials}

The datasets used and/or analysed during the current study are available from the corresponding author on reasonable request.

\section{Declarations}

\section{Ethics approval and consent to participate}

This evaluation was carried out in accordance with the National Statement on Ethical Conduct in Human Research (2007). Ethical approval for this evaluation was granted by the Northern Sydney Local Health District Human Research Ethics Committee (reference: RESP/18/247) and Macquarie University Human Research Ethics Committee (reference: 5201938347115). Participants were emailed an information sheet explaining the purpose of the study and a consent form prior to their interview date. All participants provided written informed consent to participate in the study.

\section{Consent for publication}

Not applicable.

\section{Competing interests}

The authors have declared that there are no competing interests.

\section{Received: 14 February 2021 Accepted: 25 May 2021}

Published online: 24 June 2021

\section{References}

1. United Nations; Department of Economic and Social Affairs; Population Division. World Population Ageing 2019: Highlights (ST/ESA/SER.A/430). New York: United Nations; 2019.

2. Australian Institute of Health and Welfare. Australia's health 2016. Australia's health series no. 15. Cat. no. AUS 199. Canberra: AlHW; 2016.

3. Dwyer R, Gabbe B, Stoelwinder JU, Lowthian J. A systematic review of outcomes following emergency transfer to hospital for residents of aged care facilities. Age Ageing. 2014;43(6):759-66.

4. Australian Institute of Health and Welfare. Emergency department care 2016-17: Australian hospital statistics. Canberra: AlHW; 2017.

5. Kessler C, Williams MC, Moustoukas JN, Pappas C. Transitions of care for the geriatric patient in the emergency department. Clin Geriatr Med. 2013;29(1): 49-69.

6. Morphet J, Innes K, Griffiths DL, Crawford K, Williams A. Resident transfers from aged care facilities to emergency departments: can they be avoided? Emerg Med Australas. 2015;27(5):412-8.

7. Caplan GA. A meta-analysis of "hospital in the home". Med J Aust. 2013; 198(4):195-6.

8. Fan L, Hou XY, Zhao J, Sun J, Dingle K, Purtill R, et al. Hospital in the Nursing Home program reduces emergency department presentations and hospital admissions from residential aged care facilities in Queensland, Australia: a quasi-experimental study. BMC Health Serv Res. 2016;16:46.

9. Kane RL, Keckhafer G, Flood S, Bershadsky B, Siadaty MS. The effect of Evercare on hospital use. J Am Geriatr Soc. 2003:51(10):1427-34.

10. Marshall EG, Clarke B, Burge F, Varatharasan N, Archibald G, Andrew MK. Improving continuity of care reduces emergency department visits by longterm care residents. J Am Board Fam Med. 2016;29(2):201-8.
11. Testa L, Seah R, Ludlow K, Braithwaite J, Mitchell RJ. Models of care that avoid or improve transitions to hospital services for residential aged care facility residents: an integrative review. Geriatr Nurs. 2020;41(4):360-72.

12. Testa L, Hardy JE, Jepson T, Braithwaite J, Mitchell RJ. Health service utilisation and health outcomes of residential aged care residents referred to a hospital avoidance program: A multi-site retrospective quasiexperimental study. Australas J Ageing. 2021;ST/ESA/SER.A/430:1.

13. Donabedian A. Evaluating the quality of medical care. Milbank Quarterly. 2005;83(4):691-729.

14. Gruneir A, Silver MJ, Rochon PA. Emergency department use by older adults: a literature review on trends, appropriateness, and consequences of unmet health care needs. Med Care Res Rev. 2011;68(2):131-55.

15. Arendts G, Reibel T, Codde J, Frankel J. Can transfers from residential aged care facilities to the emergency department be avoided through improved primary care services? Data from qualitative interviews. Australasian Journal on Ageing. 2010;29(2):61-5.

16. Stokoe A, Hullick C, Higgins I, Hewitt J, Armitage D, O'Dea I. Caring for acutely unwell older residents in residential aged-care facilities: perspectives of staff and general practitioners. Australas J Ageing. 2016;35(2):127-32.

17. McCusker J, Karp I, Cardin S, Durand P, Morin J. Determinants of emergency department visits by older adults: a systematic review. Acad Emerg Med. 2003;10(12):1362-70

18. Centre for Epidemiology and Evidence. Health Statistics New South Wales Sydney: NSW Ministry of Health; [cited 2020 June 26]. Available from: www. healthstats.nsw.gov.au.

19. ARRT brochure [cited 2021 April 12]. Available from: https://www.nslhd.hea Ith.nsw.gov.au/Services/Documents/SDDocs/ARRT_brochure.pdf.

20. Lavrakas PJ. Encyclopedia of survey research methods; 2008.

21. Dolbier CL, Webster JA, McCalister KT, Mallon MW, Steinhardt MA. Reliability and validity of a single-item measure of job satisfaction. Am J Health Promot. 2005;19(3):194-8.

22. QSR International. NVivo [Software]. Version 12. 2018. Available from: https:// www.qsrinternational.com/nvivo-qualitative-data-analysis-software/home.

23. Campbell JL, Quincy C, Osserman J, Pedersen OK. Coding in-depth Semistructured interviews: problems of unitization and Intercoder reliability and agreement. Sociol Methods Res. 2013;42(3):294-320.

24. Maher C, Hadfield M, Hutchings $M$, de Eyto A. Ensuring rigor in qualitative data analysis: a design research approach to coding combining NVivo with traditional material methods. Int J Qual Methods. 2018;17(1): 1609406918786362.

25. DETECT for RACF - Recognising and managing the Deteriorating Resident [cited 2021 April 12]. Available from: https://sydneynorthhealthnetwork.org.a u/wp-content/uploads/2020/01/Flyer-Deteriorating-Resident-ARRT-006.pdf.

26. Carter N, Bryant-Lukosius D, DiCenso A, Blythe J, Neville AJ. The use of triangulation in qualitative research. Oncol Nurs Forum. 2014;41(5):545-7.

27. Tong A, Sainsbury P, Craig J. Consolidated criteria for reporting qualitative research (COREQ): a 32-item checklist for interviews and focus groups. Int J Qual Health Care. 2007;19(6):349-57.

28. Testa L, Hardy JE, Jepson T, Braithwaite J, Mitchell RJ. Comparison of health service use trajectories of residential aged care residents reviewed by a hospital avoidance program versus usual care. Arch Gerontol Geriatr. 2021; 93:104293.

29. Mitchell R, Draper B, Close J, Harvey L, Brodaty H, Do V, et al. Future hospital service utilisation in older adults living in long-term residential aged care or the community hospitalised with a fall-related injury. Osteoporos Int. 2019; 30(10):1995-2008.

30. Gnanamanickam ES, Dyer SM, Milte R, Harrison SL, Liu E, Easton T, et al. Direct health and residential care costs of people living with dementia in Australian residential aged care. Int J Geriatr Psychiatry. 2018;33(7): 859-66.

31. Burton LC, German PS, Gruber-Baldini AL, Hebel JR, Zimmerman S, Magaziner J, et al. Medical Care for Nursing Home Residents: differences by dementia status. J Am Geriatr Soc. 2001;49(2):142-7.

32. Li Q, Zheng NT, Temkin-Greener H. Quality of end-of-life care of long-term nursing home residents with and without dementia. J Am Geriatr Soc. 2013; 61(7):1066-73.

33. Dwyer T, Craswell A, Rossi D, Holzberger D. Evaluation of an aged care nurse practitioner service: quality of care within a residential aged care facility hospital avoidance service. BMC Health Serv Res. 2017;17(1):33.

34. Ouslander JG, Lamb G, Tappen R, Herndon L, Diaz S, Roos BA, et al. Interventions to reduce hospitalizations from nursing homes: evaluation of 
the INTERACT II collaborative quality improvement project. J Am Geriatr Soc. 2011:59(4):745-53.

35. Ouslander JG, Perloe M, Givens JH, Kluge L, Rutland T, Lamb G. Reducing potentially avoidable hospitalizations of nursing home residents: results of a pilot quality improvement project. J Am Med Dir Assoc. 2009;10(9):644-52.

36. Crilly J, Chaboyer W, Wallis M. A structure and process evaluation of an Australian hospital admission avoidance programme for aged care facility residents. J Adv Nurs. 2012;68(2):322-34.

37. Robinson CA, Bottorff JL, Lilly MB, Reid C, Abel S, Lo M, et al. Stakeholder perspectives on transitions of nursing home residents to hospital emergency departments and back in two Canadian provinces. J Aging Stud. 2012;26(4):419-27.

38. Amadoru $\mathrm{S}$, Rayner JA, Joseph $\mathrm{R}$, Yates $\mathrm{P}$. Factors influencing decisionmaking processes for unwell residents in residential aged care: hospital transfer or residential InReach referral? Australas J Ageing. 2018:37(2):E61-e7.

39. Ní Shé É, O'Donnell D, O'Shea M, Stokes D. New Ways of Working? A Rapid Exploration of Emerging Evidence Regarding the Care of Older People during COVID19. Int J Environ Res Public Health. 2020;17(18):32.

40. Resnick B. Transitions of care from our inception to COVID-19: what have we learned? Geriatr Nurs. 2020;41(4):355-6.

\section{Publisher's Note}

Springer Nature remains neutral with regard to jurisdictional claims in published maps and institutional affiliations.

- fast, convenient online submission

- thorough peer review by experienced researchers in your field

- rapid publication on acceptance

- support for research data, including large and complex data types

- gold Open Access which fosters wider collaboration and increased citations

- maximum visibility for your research: over $100 \mathrm{M}$ website views per year

At $\mathrm{BMC}$, research is always in progress.

Learn more biomedcentral.com/submissions 